\title{
Defecation pain and coccydynia due to an anteverted coccyx: a case report
}

Omer Salar ${ }^{1 *}$, Fizza Mushtaq ${ }^{2}$ and Mushtaq Ahmed ${ }^{3}$

\begin{abstract}
Introduction: Defecation pain is a common problem with many etiologies implicated. Elucidating a cause requires a thorough medical history, examination and appropriate investigations, which may include endoscopy, barium enema, examination under anesthesia and magnetic resonance imaging or computed tomography. Coccydynia is a term used to describe pain in the region of the coccyx, often due to abnormal mobility of the coccyx. Non-surgical management options remain the gold-standard for coccydynia with surgery being reserved for complicated cases.

Case presentation: This is a case of a 67-year-old Caucasian man who presented with a two-and-a-half-year history of worsening rectal pain.

Conclusion: To the best of our knowledge, we describe the first case in the literature of an abnormally mobile anteverted coccyx causing predominantly defecation pain and coccydynia, successfully treated by coccygectomy. When first-line investigations fail to elucidate a cause of defecation pain one must, in the presence of unusual symptoms, consider musculoskeletal pathologies emanating from the coccyx and an orthopedic consultation must then be sought for diagnostic purposes.
\end{abstract}

\section{Introduction}

Defecation pain is a common problem with many causes implicated. Common causes include infective, neoplastic and anatomical or structural disorders. Coccydynia is a term used to describe pain in the region of the coccyx. Most cases have been demonstrated to be due to the abnormal mobility of the coccyx leading to fibrotic degeneration of the structure [1]. To the best of our knowledge, this is the first case report documenting an anteverted coccyx causing both chronic defecation pain and coccydynia.

\section{Case presentation}

A 67-year-old man presented with a two-and-a-half-year history of worsening rectal pain developing an hour before defecation and lasting for several hours afterwards. Otherwise our patient had normal bowel habits. There was some pain when sitting on a hard surface that lessened when sitting on a soft cushion. No pain was experienced on walking or standing. Of note, our patient had type II diabetes and ischemic heart disease. He

\footnotetext{
* Correspondence: f.mushtaq@doctors.org.uk

'Derby City General Hospital, Uttoxeter Road, Derby DE22 3NE, UK

Full list of author information is available at the end of the article
}

denied previous musculoskeletal problems, including back pain.

The rectal pain was thoroughly investigated by a consultant colorectal surgeon. Rigid sigmoidoscope and endoanal ultrasound investigations were normal. A barium enema revealed mild diverticular disease and an anorectal examination under anesthesia and subsequent biopsy revealed only a benign polyp. Double contrast magnetic resonance imaging (MRI) of his pelvis revealed no soft tissue abnormality.

Our patient was subsequently referred for consultation with an orthopedic surgeon. A physical examination revealed a patient of medium build with palpation tenderness over the tip of his coccyx, which was significantly anteverted and mobile. No tenderness was elicited over the sacroiliac joint or lumbar spine. A straight leg raise to 90 degrees was achieved and there was no neurovascular deficit in his limbs. A review of the MRI scans of his pelvis (Figures 1 and 2) and plain X-rays (Figure 2) confirmed the diagnosis of an elongated, anteverted coccyx protruding into the rectum. A standard coccygectomy was carried out, after which our patient's symptoms settled and he was discharged two months after the surgery with a good outcome.

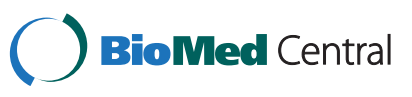




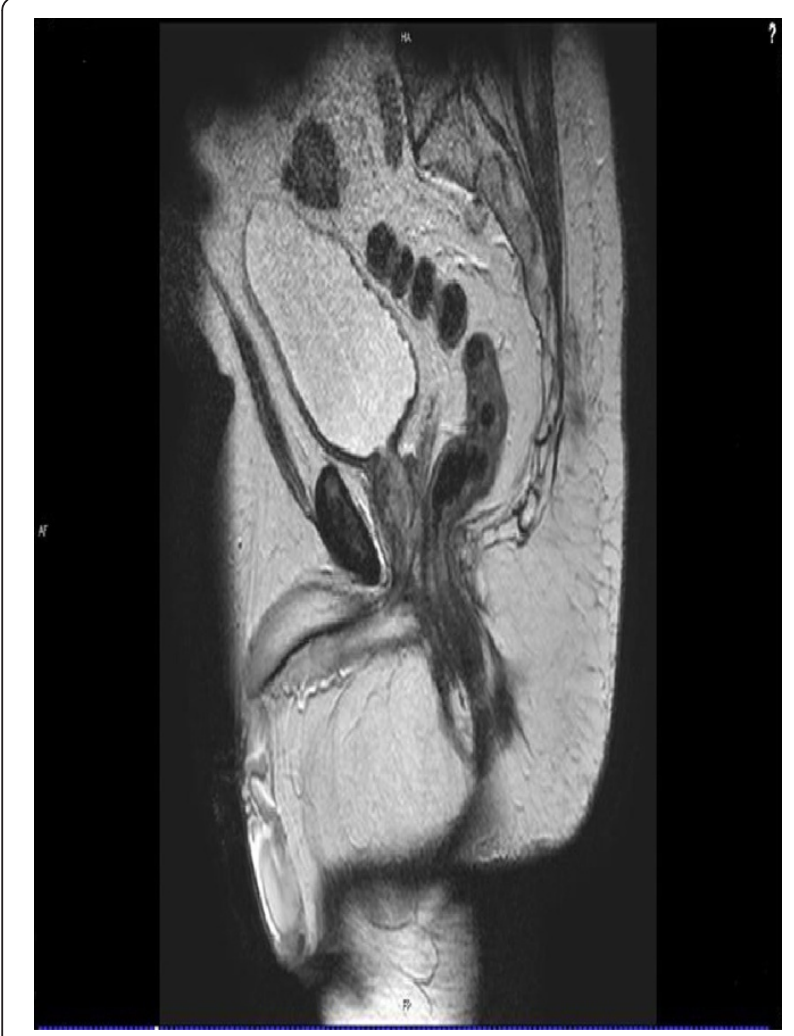

Figure 1 T2-weighted magnetic resonance image showing an anteverted coccyx and rectal impingement.

\section{Discussion}

Defecation pain is a symptom known to be caused by chronic coccydynia; especially before defecating or when constipated. Pain on defecation is a common presenting complaint. Nathan et al. describe the various causes of coccydynia and divide the etiology of coccydynia into three main categories [2]. Coccydynia can be idiopathic or traumatic in nature; various pathologies, such as those listed below, can be causative factors. Neoplastic pathologies include rectal adenocarcinomas, squamous cell anal carcinomas and rectal lymphomas being the most common. Infective processes include abscesses and anal fistulas, diverticulitis and anal papillitis and cryptitis. The final subcategory of causes of coccydynia includes somatic disorders.

The coccyx consists of three to five vertebral units that, except for the first, are fused together. Anatomically, the ventral surface is concave with grooves indicating lines of fusion. The dorsal aspect is convex and displays similar lines of fusion as well as multiple paired tubercles known as coccygeal articular processes [1,3-5].

Postacchini and Massobrio described four types of configurations of the coccyx and named them type I to type IV [3,4]. In type I, the coccyx is curved slightly forward, apex facing inferiorly and caudally. In type II, there is a more notable forward curvature and the apex extends

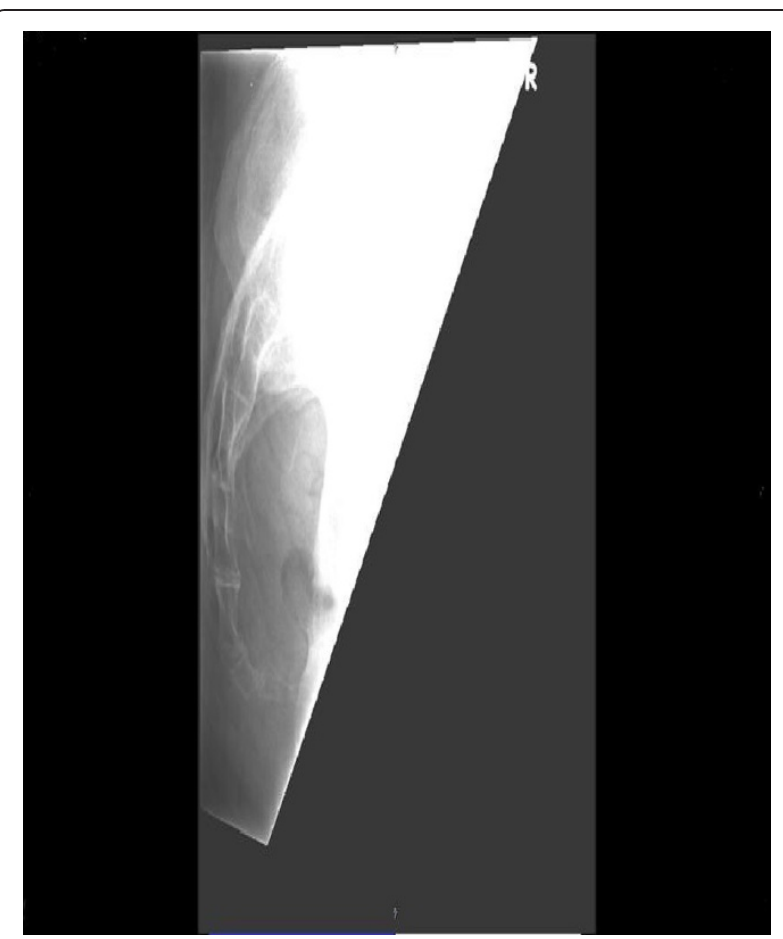

Figure $\mathbf{2}$ Lateral view X-ray showing an anteverted coccyx.

forwards. In type III, the coccyx sharply curves to the ventral side. Finally, in type IV, anatomically there is joint subluxation at either the sacrococcygeal or intercoccygeal joint [3]. The majority of coccydynia occurs in conjunction with either a subluxed or hypermobile coccyx and this pathological instability has for some time been implicated as a cause of chronic inflammatory changes [1,3-6].

Non-surgical managements have remained the gold standard for treatment of coccydynia, such as seat cushioning, coccygeal massage, stretching and manipulation, local injection of steroids or pain controlling anesthetics $[3,7]$. Conservative measures provide symptomatic relief in approximately $90 \%$ of simple cases [8,9]. Surgical intervention is typically reserved for patients with evidence of coccygeal instability, as described by Postacchini and Massobrio, such as subluxation and hypermobility or spicule formation with or without chronic symptoms that do not respond to non-surgical measures [1,10-15].

Long-term evidence exists for coccygectomy as a treatment for intractable coccydynia. Several investigators have reported results ranging from $60 \%$ to $92 \%$ success [10$15]$ whereas other authors advise against surgery. In a recent case series, $71 \%$ of patients benefited from coccygectomy and, in particular, the authors noted a correlation between histological findings and perceived benefit [1].

\section{Conclusion}

Investigating a patient with defecation pain requires a careful history and examination, including digital rectal 
examination. X-rays and endoscopy would be the first steps in determining a diagnosis. Subsequent investigations may include anorectal examination under anesthesia and barium enemas, progressing to MRI of the pelvis, particularly in the case of recurrent complicated infective processes. When first-line investigations fail to elucidate a cause of defecation pain, one must, in the presence of unusual symptoms, consider musculoskeletal pathologies emanating from the coccyx and an orthopedic consultation must then be sought for diagnostic purposes.

\section{Consent}

Written informed consent was obtained from the patient for publication of this case report and any accompanying images. A copy of the written consent is available for review by the Editor-in-Chief of this journal.

\section{Competing interests}

The authors declare that they have no competing interests.

\section{Authors' contributions}

OS made significant contributions to the design, conception, writing, drafting and final submission of the manuscript. FM contributed to the design, drafting and final editing of the manuscript. MA was the surgeon and overall supervisor for this case report; conceptualized the manuscript and approved the final draft. All authors read and approved the final manuscript.

\section{Author details}

'Derby City General Hospital, Uttoxeter Road, Derby DE22 3NE, UK. ${ }^{2}$ Birmingham City Hospital, Dudley Road, Birmingham B18 7QH, UK. ${ }^{3}$ Russells Hall Hospital, Dudley DY1 2HQ, UK.

Received: 13 December 2011 Accepted: 22 March 2012

Published: 2 July 2012

\section{References}

1. Balain B, Eisenstein SM, Alo GO, Darby AJ, Cassar-Pullicino VN, Roberts SE, Jaffray DC: Coccygectomy for coccydynia: case series and review of literature. Spine 2006, 31:E414-E420.

2. Nathan ST, Fisher BE, Roberts CC: Coccydynia- a review of pathoanatomy, aetiology, treatment and outcome. J Bone Joint Surg 2010, 92(12):1622-1627.

3. Patel R, Appannagari A, Whang PG: Coccydynia. Curr Rev Musculoskelet Med 2008, 1:223-226.

4. Maigne JY, Tamalet B: Standardized radiologic protocol for the study of common coccygodynia and characteristics of the lesions observed in the sitting position: clinical elements of differentiating luxation, hypermobility and normal mobility. Spine 1996, 21:2588-2593.

5. Postacchini F, Massobrio M: Idiopathic coccygodynia: analysis of fifty one operative cases and a radiographic study of the normal coccyx. J Bone Joint Surg 1983, 65A:1116-1124.

6. Maigne JY, Lagauche D, Doursounian L: Instability of the coccyx in coccydynia. J Bone Joint Surg 2000, 82:1038-1041.

7. Kersey PJ: Non-operative management of coccygodynia. Lancet 1980 $1: 318$

8. Thiele GH: Coccygodynia: cause and treatment. Dis Colon Rectum 1963, 6:422-436.

9. Capar B, Akpinar N, Kutluay E, Mujde S, Turan A: Coccygectomy in patients with coccydynia. Acta Orthop Traumatol Turc 2007, 41:277-280 [In Turkish]

10. Ramsey ML, Toohey JS, Neidre A, Stromberg LJ, Roberts DA: Coccygodynia: treatment. Orthopedics 2003, 26:403-405.

11. Gross NP, van Dain BE: Total coccygectomy for relief of coccygectomy: a retrospective review. J Spinal Disord 1995, 8:328-330.

12. Hellberg S, Strange-Vognsen $\mathrm{HH}$ : Coccygodynia treated by resection of coccyx. Acta Orthop Scand 1990, 61:463-465.

13. Pyper JB: Excision of the coccyx for coccydynia: a study of results in twenty eight cases. J Bone Joint Surg 1957, 39:733-737.
14. Perkins R, Schofferman J, Reynolds J: Coccygectomy for severe refractory sacrococcygeal joint pain. J Spinal Disord Tech 2003, 16:100-103.

15. Doursounian L, Maigne JY, Faure F, Chatellier G: Coccygectomy for instability of the coccyx. Int Orthop 2004, 28:176-179.

doi:10.1186/1752-1947-6-175

Cite this article as: Salar et al:: Defecation pain and coccydynia due to an anteverted coccyx: a case report. Journal of Medical Case Reports 2012 6:175.

\section{Submit your next manuscript to BioMed Central and take full advantage of:}

- Convenient online submission

- Thorough peer review

- No space constraints or color figure charges

- Immediate publication on acceptance

- Inclusion in PubMed, CAS, Scopus and Google Scholar

- Research which is freely available for redistribution 